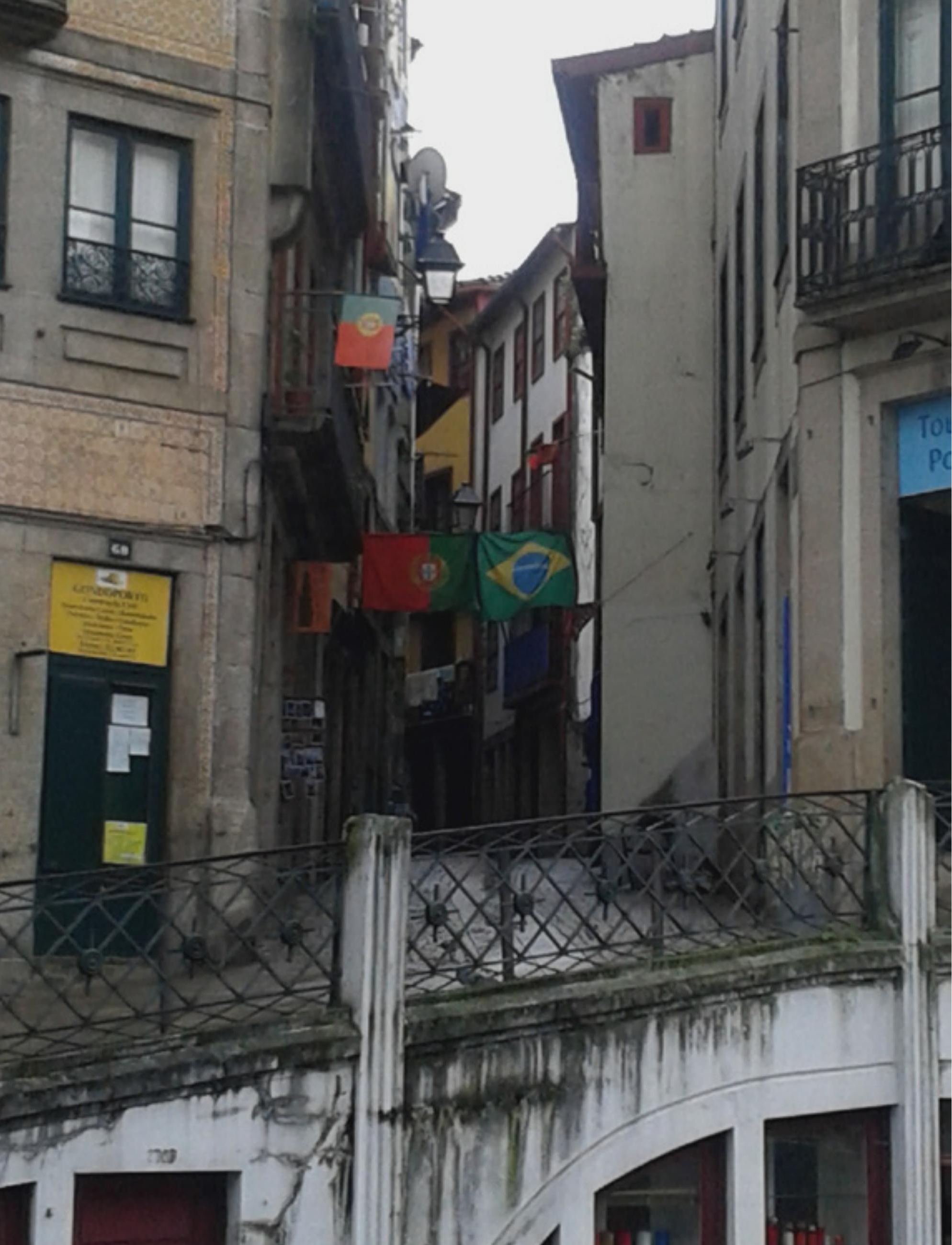




\title{
As motivações para visitar Tomar - Portugal
}

The motivations to visit Tomar - Portugal

\author{
Mafalda M. Nascimento ${ }^{1}$ \\ Nuno Abranja ${ }^{2}$ \\ Ana Ricardo Marques ${ }^{3}$
}

1 Licenciatura em Turismo, Instituto Superior de Ciências Educativas. Email: mafalda.s.nascimento@gmail.com.

2 Docente, Coordenador do Curso de Licenciatura em Turismo e Diretor do Departamento de Turismo, Instituto Superior de Ciências Educativas. Email: nuno.abranja@isce.pt.

3 Sales NH Hotels. Email: anaprmarques@gmail.com. 


\section{Resumo}

Os consumidores são influenciados por fatores internos e externos nas suas escolhas de consumo. Não são exceções as viagens e o tempo de lazer, no momento em que o visitante opta por um destino turístico.

Tomar é uma cidade já fortemente desenvolvida ao nível do turismo. Com potencial para se desenvolver ainda mais neste âmbito, a realização de um levantamento de preferências, motivações ou escolhas por parte do visitante poderão constituir uma ferramenta útil para o desenvolvimento de segmentos de mercado, desencadeando investimento em determinados produtos em detrimento de outros. Para se identificar e compreender as motivações dos viajantes que se deslocam a Tomar, foram realizados inquéritos por questionário a pessoas que já visitaram a cidade.

Neste trabalho pretende-se determinar as principais motivações do fluxo turístico de Tomar, comparando os resultados do estudo de campo com os fatores pull atuais. .

Palavras-chave: Turismo. Tomar. Motivações. Fatores pull.

\section{Abstract}

Consumers are influenced by internal and external factors regarding their consumption choices. Travelling and leisure time are no exceptions, while when a visitor chooses a destination.

Tomar is a city that has been developed for tourism. Regarding the potential to further development under a touristic perspective, a research involving preferences, motivations or choices taken by visitors could be a useful tool for directing and developing market segments, triggering actors' investment to certain products over others. To identify and understand the motivations that lead travelers to go to Tomar, relevant information was assessed by a questionnaire directed to people who have visited this city.

The present study aims to determine the main motivations of Tomar tourist flow. Research results were compared to the current pull factors.

Keywords: Tourism. Tomar. Motivations. Pull factors.

\section{INTRODUÇÃO}

Tendo como referência Tomar, uma cidade voltada para o turismo, os produtos que se julgaram pertinentes ao estudo e que serviram de base a esta investigação foram o património histórico e cultural, touring (produto touring cultural e paisagístico), aventura e natureza (produto natureza), alojamento e restauração (produto Gastronomia e Vinhos) e ainda o turismo de negócios. Todos estes fatores 
constituem fortes apostas das instituições e associações locais, que têm por base a exploração e dinamização dos recursos endógenos, segundo o modelo de desenvolvimento regional (Associação para o Desenvolvimento do Ribatejo Norte [ADIRN], 2015). Dada a escassez de informação atualizada relativamente ao peso relativo daqueles produtos na atratividade de turistas e visitantes a Tomar, os esforços foram ao encontro da oferta e portanto dos efeitos pull (atrativos) que possam eventualmente influenciar as decisões. Os dados primários foram obtidos através de inquéritos por questionário. Uma vez que os dados secundários do Turismo local indicam que a maior parte dos visitantes se enquadram no conceito de turismo interno, os questionários foram direcionados a cidadãos portugueses que já se tivessem deslocado à cidade.

O presente trabalho teve como objetivos: (i) entender a envolvência dos comportamentos e motivações do turista e visitante em geral; (ii) as motivações que contribuem para os fluxos turísticos em Tomar; (iii) relacionar os resultados do estudo em campo os dados estatísticos relativos a visitas, fornecidos pelas entidades competentes; e (iv) verificar correspondências entre os resultados com os fatores pull que influenciam as escolhas dos indivíduos que se deslocam à cidade.

\section{MOTIVAÇÃO E COMPORTAMENTO DO CONSUMIDOR}

De uma forma geral, o comportamento é o conjunto de atividades físicas e mentais realizadas por consumidores, que resultam no processo de decisões e ações, para a utilização de produtos e serviços que satisfazem necessidades e desejos, pagando por eles (Cunha \& Abrantes, 2013; González Serra, 2008; Sheth, 2001 e Solomon, 1996, citados por A. Marques, comunicação pessoal, outubro de 2014). As motivações advêm das necessidades, desejos e objetivos pessoais, relacionados com o comportamento psicossociológico dos consumidores (Cunha, 2010). Tornase relevante conhecer as preferências, tendências, escolhas, motivações e desejos, porque influenciam a procura e portanto, o mercado - a oferta (A. Marques, comunicação pessoal, outubro de 2014; Cardoso \& Tavares, 2005; Chen, 2003; Sousa \& Simões, 2010; Kastenholz, 2002).

Os fatores internos e externos ao indivíduo ou empresa são determinantes na decisão de consumo. Os fatores internos são os inerentes à individualidade do consumidor (personalidade, família, gosto pessoal, motivação, grau de importância ou interesse, etc.), o ambiente em que o consumidor se insere, o conhecimento e informação a que tem acesso. Por outro lado, também o meio envolvente (externo) 
condiciona a procura, nomeadamente as influências do marketing e a situação atual do indivíduo ou empresa. Por seu turno, a envolvente sociocultural, relacionada com as classes e grupos sociais (status), estilo de vida, demografia, etc., também condiciona as motivações e escolhas (Cardoso \& Tavares, 2005; Cunha \& Abrantes, 2013; Divisekera, 2010; González Serra, 2008; Hosany \& Prayag, 2013; Medeiros \& Cruz, 2006; Pimentel, 2008; Pires, 2013; Sousa \& Simões, 2010). A motivação resulta ainda de outra vertente do ambiente a que o consumidor está exposto: à situação de uso anterior e à oferta comercial, que abrem outras oportunidades de mercado e são objetos dos estudos de mercado (Marques, 2009; Rossiter et al, 1987 e 1991, citados por Marques, 2009).

Relativamente às motivações para viagens de lazer, McIntosh (1977, citado por Marques, 2009) distingue quatro dimensões turísticas: (i) as físicas, inerentes ao corpo; (ii) as culturais, relativas ao conhecimento; e duas sociais, sendo uma relacionada com (iii) o status e prestígio, e a outra com (iv) as relações interpessoais). Murphy (1985, citado por Marques, 2009) relaciona a dimensão física de McIntosh com a necessidade de descanso e relaxamento e adiciona uma nova dimensão, a da fantasia ou aventura. Neste caso, o indivíduo viaja por necessidade de usufruir de novas experiências, necessidade essa que não se inclui na esfera de motivações culturais, pois a mudança de ambiente pode funcionar apenas como resposta a sentimentos negativos do quotidiano (Ulrich, 1983 e Harting et al, 1991, citados por Marques, 2009). Desta forma, as emoções e as expectativas de gratificação do viajante determinam as preferências relativamente aos destinos de viagem (Bansal \& Eiselt, 2004; Murphy, 1985, citado por Marques, 2009). O estudo do comportamento do turista ajuda nas estratégias de marketing por parte dos produtores, segmentação dos mercados-alvo em que apostar, e na identificação de oportunidades de mercado. São as exigências de quem compra que ajudam a delinear os objetivos e direcionam tanto o desenvolvimento de produtos como a estratégia de mercado para as vendas (Cardoso \& Tavares, 2005; Chen, 2003; Sousa \& Simões, 2010; Kastenholz, 2002). A oferta resultante deve adaptar-se à procura (Cunha, 2010), passando-se assim a falar de fatores pull, como sendo aqueles que atraem um ou certos segmentos em detrimento de outros (Correia, Vale \& Moço, 2007).

\section{A CIDADE DE TOMAR}

Tratando-se de uma cidade histórica, a oferta relativa à componente turística divide-se essencialmente nas vertentes relativas ao património arquitetónico e cultural e aos recursos turísticos (serviços, alojamento, restauração e bebidas). 


\subsection{Património arquitetónico}

Tomar é uma cidade muito rica em monumentos, essencialmente ligados à Idade Média, no seguimento da presença das ordens militares que ali tiveram base, como a Ordem dos Pobres Cavaleiros de Cristo (Templários) e Ordem de Cristo (Tomar Cidade Templária, 2015). Uma atração relevante parece ser o Convento de Cristo, Património Mundial da UNESCO em 1983. Tendo sido local da coroação de Filipe I, sede da Ordem de Cristo e albergado o seu Grão-Mestre Infante D. Henrique, o monumento tornou-se símbolo nacional pela arquitetura Manuelina da Janela do Capítulo e pela Charola octogonal, oratório templário românico de influência oriental do século XII (Câmara Municipal de Tomar, 2005; Tomar - Cidade Templária, 2015). Não menos importante, a Igreja de Nossa Senhora dos Olivais, datada do século XII, sede Templária e Panteão dos Grão-Mestres Templários, entretanto destruído pela Inquisição (Câmara Municipal de Tomar, 2005). O visitante ou turista pode ainda deslumbrar-se com outros monumentos, como sendo o (i) Aqueduto dos Pegões, para abastecimento do Convento, criação de Filipe de Terzi; a (ii) Ermida de Nossa Senhora da Conceição (séc. XVI), concebida por João de Castilho, constitui um exemplo do classicismo italiano e a melhor evocação da arte greco-romana na Península Ibérica; a (iii) Capela de S. Gregório, com os seus painéis de azulejos setecentistas; o (iv) Convento de Santa Iria, a padroeira da cidade, com azulejos do século XVII, e um retábulo de Cristo crucificado atribuído a João de Ruão; o (v) Convento de S. Francisco, maneirista, albergando uma escultura de um raro Calvário; e a (vi) Ermida de Nossa Senhora da Piedade, do século XIV, no alto da sua longa escadaria (Tomar - Cidade Templária, 2015).

\subsection{Herança cultural}

Entre os museus, encontram-se o Municipal João de Castilho, Museu Hebraico Abraão Zacuto, a Coleção Visitável "Museu dos Fósforos" e o Arquivo Fotográfico Silva Magalhães. O primeiro alberga os núcleos de Arte Antiga, de Arte Naturalista e de Arte Contemporânea. O segundo, encontra-se na Sinagoga de Tomar e integra livros e objetos da tradição e culto judaicos. Com cerca de 80.000 objetos, o Museu dos Fósforos dá a conhecer a introdução e o fabrico dos fósforos em Portugal. Por último, o Arquivo Fotográfico Silva Magalhães possui um reportório de imagens, essencialmente dos séculos XIX e XX, sobre os mais variados temas (Tomar - Cidade Templária, 2015). 


\subsection{Feiras, conferências e congressos}

O município mostra ser muito ativo relativamente a festas e romarias, que dinamizam fortemente a cidade, constituindo um forte fator pull. A maior parte das feiras parecem destinar-se à promoção da gastronomia local e entre as mais importantes encontra-se o Congresso da Sopa, onde são servidas sopas pela restauração e bebidas do município; a Festa dos Tabuleiros, que conta com ruas decoradas pela população local e cortejos e que ocorre de quatro em quatro anos; a Festa Templária, também anual; a Feira das Passas (ou de Santa Iria), também muito visitada, anualmente; a Feira da Laranja Conventual, que consiste numa venda solidária de doçaria, licores e compotas conventuais confecionados a partir daquele fruto; "Todos com feijão, o feijão com todos", mostra organizada em outubro de cada ano pela Câmara Municipal de Tomar, em que os restaurantes aderentes organizam desde pratos confecionados com feijão; Tomar Alternativo, um evento que tem como objetivo promover a exposição e comercialização de produtos artesanais, tradicionais, regionais, gourmet e biológicos em "segunda mão" e de divulgar animações, jogos e atividades de lazer; a Compre Connosco, uma feira de artesanato mais discreta; e a Feira de Artes, Colecionismo e Velharias, que conta com um cortejo temático na Mata dos Sete Montes e com arraiais no jardim da Várzea Pequena, junto ao rio, com petiscos, música, bandas filarmónicas e ranchos folclóricos (Festa Templária, 2015; Tomar - Cidade Templária, 2015).

Relativamente ao produto Turismo de Negócios, em Tomar existe apenas o reconhecido Hotel dos Templários e o Convento de Cristo para a realização de congressos e conferências (Direção-Geral do Património Cultural [DGPC], 2015; Hotel dos Templários, 2015).

\subsection{Alojamento e restauração}

Segundo o sítio da internet da Câmara Municipal (2015), a oferta é grande e variada relativamente ao alojamento contando com treze empreendimentos no regime hoteleiro, seis em Turismo em Espaço Rural (TER) e três na categoria dos parques de campismo (Tomar - Cidade Templária, 2015). Recentemente surgiram dois hostels (Booking.com, 2015a e b).

No que diz respeito à restauração e bebidas só no centro histórico existem, atualmente, trinta e sete estabelecimentos, dos quais vinte e cinco servem comida tradicional e um fast food. Contam-se ainda quatro fora do centro histórico e mais dezassete restaurantes próximos, sendo que um destes últimos é de renome além município (Tomar - Cidade Templária, 2015). 
O produto Gastronomia e Vinhos é uma aposta de relevo em Tomar. Na Gastronomia, podem-se enumerar uma variedade de pratos tradicionais da região, alguns endógenos, especialmente na doçaria conventual: as Fatias de Tomar e os Beija-me Depressa são especialidades exclusivas da região. Pode-se ainda destacar, numa grande variedade, os pratos de lampreia, sável, bacalhau, cabrito, dobrada, cabidelas, morcelas de arroz e coelho na abóbora. Nas confeitarias estão expostas as castanhas de ovos, queijadas de amêndoa e doces de gila. Nos Vinhos, a reputação é essencialmente alimentada pelos prémios nacionais concedidos à Quinta Solar dos Loendros, Quinta do Cavalinho, Quinta do Casal das Freiras e Quinta Encosta do Sobral (Tomar - Cidade Templária, 2015).

\section{ESTRATÉGIA TURÍSTICA LOCAL}

Em termos históricos, a primeira metade do século XX foi marcada pela preservação de património arquitetónico de maior significado histórico. No entanto, nas últimas cinco décadas, a herança cultural tem-se tornado uma das maiores motivações de um número crescente de pessoas, especialmente no espaço europeu (Lopes, 2000).

O consumo cultural parece estar relacionado a um estilo de vida associado a um estrato social particularmente relacionado a certas idades, ocupação social, rendimentos, status social e especialmente ao nível da formação académica. $O$ turismo cultural assumiu tal relevância, que se tornou estratégia de marketing do destino (Semedo, 2008). Em termos de distribuição, em detrimento ao marketing direto e promoções associadas aos diversos canais, a cidade parece beneficiar maioritariamente da informação disponível em: (i) portais de turismo e websites em geral, onde se incluem o do município, por exemplo (ADIRN, 2015; DGPC, 2015; Tomar - Cidade Templária, 2015; Turismo do Centro, 2015); (ii) agências tradicionais e online (Booking.com, 2015, entre outras); (iii) brochuras e panfletos (Câmara Municipal de Tomar, 2005); (iv) comunicação via consumidor final, por fidelização do cliente e pelo chamado na gíria de "boca-em-boca"; e (v) pelas redes sociais, nomeadamente pelo Facebook, onde se podem encontrar páginas de informação turística como a do "Convento de Cristo", "Made in Tomar", "Tomar na Rede" e a da Câmara Municipal, denominada "Tomar Templária".

No quadro 1 encontra-se o número de dormidas efetuadas por turistas do mercado nacional e estrangeiro em estabelecimentos hoteleiros na região Centro, pela Nomenclatura das Unidades Territoriais para Fins Estatísticos de nível II (NUTS II). O quadro indica que o segmento de mercado mais importante a explorar e a atrair é o nacional, por ter um maior peso em termos de chegadas (Pires, 2013). 
Quadro 1 - Número de dormidas (milhares) nos estabelecimentos hoteleiros na região Centro. Dados referentes ao período compreendido entre 2002 e 2011.

\begin{tabular}{|l|r|r|r|r|r|r|r|r|r|r|}
\cline { 2 - 11 } \multicolumn{1}{c|}{} & \multicolumn{10}{|c|}{ ANOS } \\
\hline NUTS II & $\mathbf{2 0 0 1}$ & $\mathbf{2 0 0 3}$ & $\mathbf{2 0 0 4}$ & $\mathbf{2 0 0 5}$ & $\mathbf{2 0 0 6}$ & $\mathbf{2 0 0 7}$ & $\mathbf{2 0 0 8}$ & $\mathbf{2 0 0 9}$ & $\mathbf{2 0 1 0}$ & $\mathbf{2 0 1 1}$ \\
\hline Centro & 1.953 & 2.020 & 3.111 & 3.297 & 3.508 & 3.851 & 3.880 & 3.748 & 3.885 & 4.044 \\
\hline Estrangeiro & 548 & 551 & 1.067 & 1.080 & 1.211 & 1.395 & 1.401 & 1.293 & 1.342 & 1.551 \\
\hline Portugal & 1.405 & 1.469 & 2.044 & 2.217 & 2.298 & 2.456 & 2.479 & 2.455 & 2.542 & 2.493 \\
\hline
\end{tabular}

Fonte: Adaptado de anuário Estatístico do Turismo - Turismo de Portugal, 2011, citado por Pires, 2013

Após este enquadramento, torna-se pertinente inquirir os turistas e viajantes do mercado nacional, acerca das suas motivações, e enquadrá-los na oferta turística de Tomar.

\section{METODOLOGIA}

Toda a investigação seguiu os passos sugeridos por Quivy e Campenhoudt (2003).

O estudo teve início no levantamento de informação teórica geral e relativa ao município em foco, com o propósito de se reunir e organizar ideias para o delineamento do inquérito por questionário. 0 método de Inquérito por Questionário é vantajoso por tornar possível a aquisição de múltiplos dados (passíveis de ser correlacionados), numa nocturna es quantitativa (Quivy \& Campenhoudt, 2003).

O questionário era composto por uma pergunta-filtro, eliminatória no caso do inquirido nunca se ter deslocado à cidade. Seguiu-se a identificação de fatores sociodemográficos, a caracterização do seu perfil e ainda uma série de indicadores relativos às motivações para viajar e para visitar Tomar.

Optou-se por não tornar obrigatória a questão dos rendimentos dos inquiridos, por se tratar de uma questão demasiado delicada para alguns. As perguntas que o constituíam eram (Abranja, 2013; Gonçalves, 2011):

1. Pergunta-filtro, que rejeita o inquirido que nunca esteve em Tomar.

2. Perguntas de escolha múltipla:

2.1. De avaliação e, como tal, com recurso a graus de intensidade (Escala de Likert). Foi utilizada a forma de escala com grau par, para levar o inquirido a manifestar-se, embora se corra o risco de obter uma má resposta quando, de facto, o indivíduo não tem aquela opinião.

2.2. Em leque fechado, em que o inquirido deveria escolher uma opção, ou mais, entre as fornecidas.

3. Dicotómicas, em respostas exclusivas (sim/não). 
Após o preenchimento dos questionários, os dados recolhidos foram codificados em tabelas Excel e procedeu-se por fim a uma análise de conteúdo.

\section{RESULTADOS}

O questionário foi respondido via online, entre dezembro de 2014 e janeiro de 2015. Foram preenchidos 70 questionários, cuja amostra se mostrou ser representativa e aleatória, dada essencialmente o leque de idades e formações académicas.

Iniciando a análise dos resultados pelas questões sociodemográficas, os inquiridos eram maioritariamente do sexo feminino (68.6\%). Os inquiridos encontravam-se acima dos 18 anos, distribuídas pelas classes, embora a classe modal fosse a de 25-34 anos (37.1\%). Relativamente às habilitações académicas, $42.9 \%$ dos indagados frequentaram uma Licenciatura, seguindo-se $25.7 \%$ o Mestrado, $14.3 \%$ o Ensino Secundário, $19.9 \%$ o Doutoramento, $2.9 \%$ o 3 ㅇ Ciclo (9․ Ano) e $1.4 \%$ o 1 을 Ciclo (4a classe). A resposta à questão referente aos rendimentos, como anteriormente referido, não era obrigatória. Na amostra em foco, dois inquiridos não responderam. Dos $97.1 \%$ que responderam, embora todas as classes estivessem representadas, os resultados evidenciam que $32.8 \%$ apresentava um rendimento entre $500-999 €, 27.1 \%$ entre $1000-1499 €$ e $18.6 \%$ entre $1500-1990 €$.

Cerca de $87.1 \%$ dos indagados revelaram que costumam realizar viagens de férias ou de lazer em Portugal, dormindo fora da residência habitual. No planeamento dessas viagens, $90.0 \%$ utiliza a internet e apenas $2.9 \%$ recorre a agências de viagens. Cerca de $1.4 \%$ recolhem informação nos Postos de Turismo e $5.7 \%$ noutros locais, podendo consultar, por exemplo, outras delegações, amigos ou familiares. Quando planeiam pernoitar no destino, $95.7 \%$ dos inquiridos são os responsáveis pela procura do próprio alojamento. Na escolha do local a visitar, os indicadores determinantes (grau de importância 4) são os preços (71.4\%), seguida da localização (57.1\%), património histórico arquitetónico (55.7\%), cultura (tradições, festas e feiras, com 50.0\%), natureza e conforto (44.3\% para cada indicador), acolhimento (38.6\%), alojamento (37.2\%), facilidades de acesso e serviços ao dispor (37.2\%, cada), restauração (37.2\%), exposições $(20.0 \%)$, atividades de animação turística (18.6\%), desportos ou nocturna es radicais (15.7\%) e menos importante, a vida nocturna (8.6\%). Com um grau de importância 3, a lista é encabeçada pela restauração e gastronomia (54.3\%), seguindo-se o alojamento e acolhimento (52.9\%). Por último, a vida nocturna e os desportos radicais não têm relevância na escolha (24.3 e $27.1 \%$, respetivamente, importância grau 1 ).

Relativamente ao perfil do inquirido, $80.0 \%$ procura conhecer locais que ainda não tenha visitado. Outras características relevantes são também o interesse por assuntos variados e a vontade de experimentar novos produtos gastronómicos (62.9\%, cada). 
Por fim, ainda com alguma significância, encontra-se o gosto por experimentar novas nocturna es (58.6\%). Os indivíduos referiram ainda que apreciam a ideia de mudança (60.0\%) e que portanto, dão preferência ao desconhecido (45.7\%).

Passando ao foco do estudo, o município de Tomar, $42.8 \%$ dos indagados visitaram a cidade mais de três vezes, e $22.9 \%$ apenas uma vez. Nessas visitas, $44.3 \%$ das pessoas dormiram no local, essencialmente no Hotel dos Templários (34.0\%), mas também na casa de familiares e amigos ou num estabelecimento hoteleiro até $3 * * *$ (25.0\%, cada); cerca de $11.4 \%$ dos turistas dormiram em casas de Turismo em Espaço Rural. Poucos pernoitaram em parques de campismo ou hostels (2.3\%, cada). Naquelas visitas, $77.1 \%$ dos visitantes procuraram conhecer a gastronomia local.

Os fatores mais importantes que levaram os turistas e visitantes a Tomar foram essencialmente o conhecimento da história do país (35.7\%), descoberta da cultura da região (34.3\%), quebra da rotina diária (27.1\%) ou fuga ao dia-a-dia ou relaxamento e sossego (22.9\%, cada) ou libertação de estresse (20.0\%) e rever amigos e família (14.3\%). São insignificantes os motivos de visita a locais onde os conhecidos nunca estiveram (45.7\%) e contar a outros a experiência de férias (51.4\%).

Quanto à forma como os visitantes ou turistas passaram o tempo em Tomar (figura 1), o resultado encontra-se claramente voltado para a vertente do património histórico (22.3\%). Segue-se o produto Gastronomia e Vinhos (13.3\%) e a intenção de relaxamento e descanso (10.3\%). Seguem-se os eventos culturais na temática Templária (animação, jantares e outros eventos Templários, com 9.9\%, e visitas a museus, com $8.8 \%$ ). Os inquiridos dedicaram pouco tempo a desportos de aventura $(2.6 \%$,$) e praticamente não investiram o seu tempo em vida nocturna (1.7\%).$

Figura 1 - Ocupação do tempo pelos visitantes e turistas que se deslocaram a Tomar.
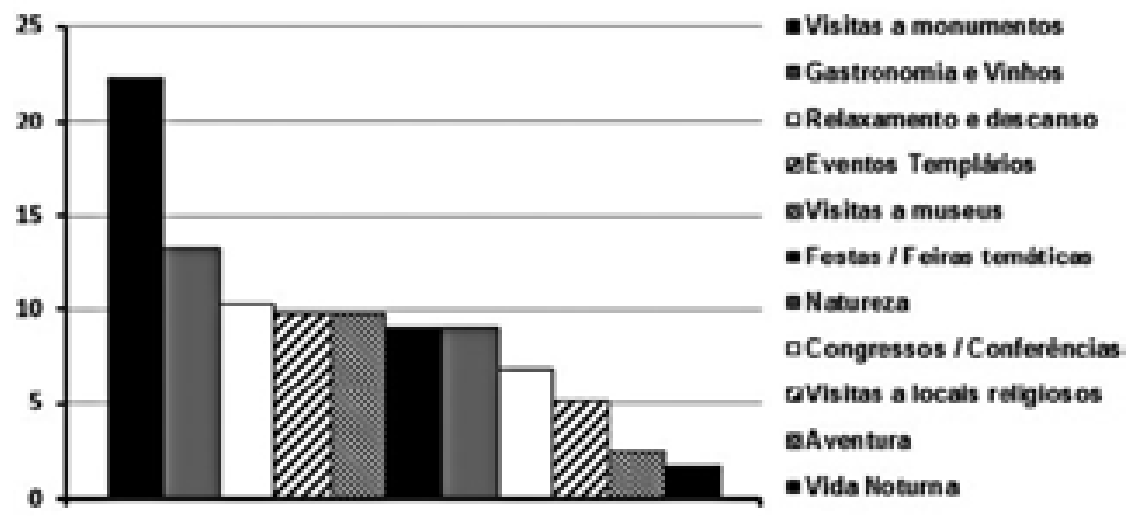

Fonte: elaboração própria 
A última questão referia-se aos fatores patrimoniais e culturais que serão mais importantes à cidade em foco (figura 2). Na opinião dos inquiridos e de forma unânime, o Convento de Cristo é o ex libris da cidade (87.1\%), seguido da Festa dos Tabuleiros e da Festa Templária (60.0\% e 47.1\%, respetivamente). Seguem-se a Sinagoga (37.1\%) e a Igreja de Sta. Maria dos Olivais (28.6\% para ambos). Também importantes são a Igreja de São João Batista e o Aqueduto dos Pegões (22.9\%, cada). Com menos importância encontram-se o Museu dos Fósforos e a Casa dos Cubos, casa esta, o edifício preferencial de exposições temporárias (1.4\%, cada).

Figura 2 - Património arquitetónico e cultural mais relevante em Tomar. Elementos provenientes dos inquéritos por questionário, segundo uma escala de importância.

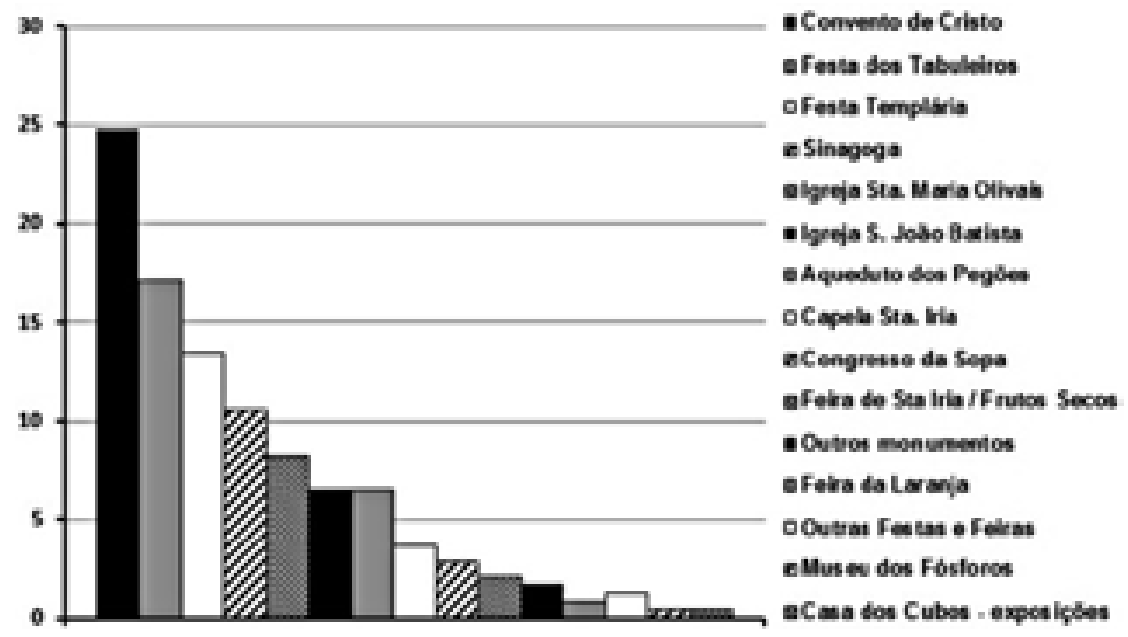

Fonte: elaboração própria

\subsection{Discussão dos Resultados}

Com base nos resultados, embora a localização e acessos, preços, serviços e acolhimento sejam os fatores determinantes na escolha de um destino, a verdade é que o património histórico se encontra entre essas principais motivações, coincidindo com a principal motivação para visitar especificamente Tomar, sobrepondo-se na perfeição aos fatores pull de maior relevância (figura 1). De facto, situada no centro do país e gozando de bons acessos a nível rodoviário e ferroviário, a cidade Templária, tão rica em património, alojamento, gastronomia e em alternativas de recreio e lazer, nomeadamente a natureza, parece atrair e cativar o viajante. A maior parte dos inquiridos deslocou-se ao município mais de três vezes, com os intuitos generalistas de visitar monumentos, festas e feiras e relaxamento, o que indicia tratar-se de um local que tem muita atratividade e capacidade de fidelização para os seus visitantes. 
O produto Gastronomia e Vinhos assume também um papel importante nas motivações e poderá especular-se se este interesse não se encontrará de facto relacionado com as Festas e Feiras, tão voltadas para esta vertente. A Feira de Sta. Iria, também conhecida por Feira dos Frutos Secos, a Festa Templária e dos Tabuleiros, a Feira da Laranja ou o Congresso da Sopa, estre outros eventos de menor notoriedade, são todos alusivos à temática. Os vinhos também têm vindo a assumir um papel importante na região pelo aumento da sua qualidade (ADIRN, 2015, Tomar - Cidade Templária, 2015).

$\mathrm{Na}$ questão relativa ao alojamento onde pernoitaram, optou-se por constituir o Hotel dos Templários como opção individual em detrimento à opção mais generalista de alojamento, por ser o único local com um centro de congressos, eventual motivo de algumas deslocações à cidade. Esta decisão permitiu identificar que apenas 6.9\% se teriam deslocado a Tomar por motivos de Turismo de Negócios, incluídos nos $34.0 \%$ de inquiridos que pernoitaram naquele hotel, nas suas deslocações à cidade.

Os resultados apontam ainda para uma sobreposição com a informação proveniente do Convento de Cristo e Posto de Turismo de Tomar, relativamente a 2015. O Convento de Cristo - Património da UNESCO, a Sinagoga como o único templo hebraico proto-renascença existente no nosso país, e a Igreja de Sta. Maria dos Olivais enquanto panteão e sede Templária, são referências. Também a Igreja de S. João Baptista, relacionada com a Ordem Templária, se une se une ao aqueduto de Felipe de Terzi para constituírem, no seu conjunto, elementos pull para os mais intelectuais. A Capela de Santa Iria surge como sendo também importante para Tomar, pois a santa é a padroeira da cidade e encontra-se envolta em lendas. A assumir uma grande relevância, encontram-se as principais festas da cidade, como a dos Tabuleiros e a Templária, que se posicionam logo em segundo e terceiro lugares na importância da herança patrimonial em Tomar. Intercalam-se assim no rank do património histórico, surgindo logo após a preferência maior, o Convento de Cristo (figura 2). Na realidade, os resultados são praticamente coincidentes com os gentilmente cedidos pelo Convento de Cristo e Posto de Turismo de Tomar. Assim, relativamente ao Convento, o monumento recebeu, em 2014, 209.294 visitantes - um aumento face aos 191.278 que recebera no ano anterior -, dos quais $61 \%$ eram nacionais e $39 \%$ estrangeiros. Relativamente a 2014 , a Sinagoga recebeu 37.632 visitantes (66\% eram estrangeiros), a Igreja de Santa Maria dos Olivais 9.806 pessoas ( $73 \%$ dos quais portugueses), a Capela de Santa Iria 12.740 (71.7\% eram portugueses). Não existem registos relativamente à Igreja São João Batista, também Templária. Nas Festas e Feiras do ano de 2014, excetuando a Festa dos Tabuleiros, que se realiza a cada 4 anos (última edição contabilizada ocorreu a 2011), o panorama é mais variável. A Festa dos Tabuleiros contou com cerca de 600.000 pessoas, a Festa Templária com cerca de 40.000, a Feira de Santa Iria / Frutos Secos com 
35.000 e o Congresso da Sopa com 3.000. Neste seguimento, apenas a Feira de Santa Iria e o Congresso da Sopa se encontram na ordem inversa do que foi postulado pelos inquiridos, relativamente à importância destes eventos para Tomar, tal como acontece com a Igreja de Santa Maria dos Olivais e a Capela de Santa Iria (figura 2).

\section{CONCLUSÕES}

O presente trabalho teve como objetivos entender as motivações dos visitantes, sejam turistas ou visitantes do dia, da cidade de Tomar. Na presente investigação recorreu-se à realização de questionários online, direcionados a um leque de pessoas que já teriam visitado a cidade.

Segundo as tipologias relativas às motivações identificadas por Cunha (2003), o visitante que se desloca a Tomar é essencialmente o "culturalmente motivado". Parafraseando o autor, estes viajantes são aqueles para quem a cultura é a motivação determinante da viagem. Não há dúvida que dado o património que possui, símbolos da Identidade Nacional, a cidade tem apostado em variados eventos, atingindo vários segmentos de mercado. Todas estas apostas vão aliás ao encontro das sugestões do Plano Estratégico Nacional do Turismo (2007) e sua revisão (2010), que considerava a cultura como uma vertente a desenvolver e a gastronomia como um dos principais recursos da região Centro de Portugal (NUTS II).

A investigação permitiu concluir que a oferta turística, nomeadamente os fatores pull arquitetónicos e culturais de Tomar, vão ao encontro das motivações e preferências que levam os viajantes a escolher um destino. Mais ainda, os resultados são em grande parte concordantes com os dados cedidos pelo Convento de Cristo e Porto de Turismo de Tomar, relativamente ao número de visitantes por atração arquitetónica e cultural. Uma vez que os resultados foram coerentes, pode concluir-se que a amostra foi aleatória e representativa.

Por sua vez, os resultados respeitantes às motivações e aos fatores considerados importantes para Tomar coincidem com o foco, a vários níveis, realizado por parte das entidades competentes. As entidades institucionais e associativas locais têm vindo a apostar na cultura, recreio e lazer, nomeadamente em feiras e mostras gastronómicas, como forma de gerar riqueza local, a nível económico-social, com base no turismo enquanto motor do desenvolvimento regional (ADIRN, 2015; Tomar - Cidade Templária, 2015).

Dada a escassez de informação acerca das motivações das deslocações por parte dos visitantes e turistas a Tomar, o presente trabalho enquadra pela primeira vez a relevância atual das Festas e Feiras no panorama geral da oferta patrimonial. 


\section{REFERÊNCIAS}

ABRANJA, Nuno. Instrumentos de análise III - Inquéritos por questionário. Licenciatura em Turismo. Ramada: Instituto Superior de Ciências Educativas, 2013.

ADIRN, Associação para o Desenvolvimento Integrado do Ribatejo Norte. Retirado de http://www.adirn.pt/, 2015.

BANSAL, $\mathrm{H}$; EISELT H. A. Exploratory research of tourist motivations and planning. Tourism Management, 25, 387-396, 2004.

BOOKING.COM. Hostel 2300 Thomar. Retirado de http://www.booking.com/searchresults.en-gb.html?aid=375018;label=tomar-IM_WZmpilSZum8kQZAq4YQS3397 4619991\%3Apl\%3Ata\%3Ap1\%3Ap2\%3Aac\%3Aap1t2\%3Aneg;sid=eae47b7840be40 76ea87ca7ba3b3a085; dcid=4;city=-2177563; hyb_red=1;redirected $=1$; redirected_ from_city $=1$; source $=$ city; src=city \&, 2015a.

BOOKING.COM. Residencial Avenida Hostel. Retirado de http://www.booking. com/searchresults.en-gb.html?aid=375018;label=tomar-IM_WZmpilSZum8 kQZAq4YQS33974619991\%3Apl\%3Ata\%3Ap1\%3Ap2\%3Aac\%3Aap1t2\%3An eg;sid=eae47b7840be4076ea87ca7ba3b3a085; dcid=4;city=-2177563; hyb_ red=1;redirected=1;redirected_from_city $=1$; source=city; $s r c=c i t y \&, 2015 b$.

CÂMARA MUNICIPAL DE TOMAR. Tomar, Cidade Templária. Tomar: Gabinete de Publicações CMT, 2005.

CARDOSO, Paulo Ribeiro; TAVARES, Marcos Alexandre. Estilos de vida e comportamento de consumo: uma análise conceptual. Revista da Faculdade de Ciências Humanas e Sociais da Universidade Fernando Pessoa, 2, pp.117-132, 2005

CHEN, Joseph S. Market segmentation by tourists' sentiments. Annals of Tourism Research, 30(1), pp.178-193, 2003.

CORREIA, António; DO VALE, Patrícia Oom; MOÇO, Cláudia. Modeling motivations and perceptions of Portuguese tourists. Journal of business Research, 60, pp.76-80, 2007. CUNHA, Licínio. Perspetivas e tendências do Turismo. Lisboa: Edições Universitárias Lusófonas, 2003.

CUNHA, Licínio. Economia e política do turismo. 3a ed. Lisboa: Lidel, 2013.

CUNHA, Licínio; ABRANTES, António. Introdução ao turismo. 5a ed. Lisboa: Lidel, 2013.

DIVISEKERA, Sarath. Economics of tourist's consumption behaviour: Some evidence from Australia. Tourism Management, 31, pp.629-636, 2010.

DGPC - Direção Geral do Património Cultural. DGPC. Retirado de http://www.patrimoniocultural.pt/patrimonio/patrimonio-movel/pesquisa-do-patrimonio/classificado-ou-em-vias-de-lassificacao/geral/view/73123, 2015.

FESTA TEMPLÁRIA. Programa da Festa Templária. Retirado de http://www.festatemplaria.ipt.pt/pt/programa.html, 2015.

GONÇALVES, Helena. Estudos de Mercado. Curso de Empreendedorismo de Base Científica e Tecnológica. Oficina de Transferência e de Conhecimento [OTIC]. Lisboa: Universidade Técnica de Lisboa, 2011. 
GONZÁLES SERRA, Diego Jorge. Psicología de la motivación. La Habana: Editorial Ciencias Médicas, 2008.

HOSANY, Sameer; PRAYAG, Girish. Patterns of tourists' emotional responses, satisfaction, and intention to recommend. Journal of Business Research, 66(6), pp.730-737, 2013.

HOTEL DOS TEMPLÁRIOS. Hotel dos Templários. Retirado de http://www.hoteldostemplarios.pt/localizacao/pt/contactos, 2015.

KASTENHOLZ, Elisabeth. The role and marketing implications of destination images on tourist behavior: The case of Northern Portugal. Tese de Doutoramento. Aveiro: Universidade de Aveiro, 2002.

LOPES, Flávio. O programa de incremento do turismo cultural: Dos novos conceitos e motivações sobre o património cultural à criação de produtos turísticos de qualidade. Antropológicas, 4, pp.243-249, 2000.

MEDEIROS, Janine Fleith; CRUZ, Cassiana Maris Lima. Comportamento do consumidor: Fatores que influenciam no processo de decisão de compra dos consumidores. Passo Fundo: Teoria e Evidência Económica, 14, pp.167-190, 2006.

MARQUES, Carlos. Motivações das viagens turísticas para regiões do interior: $\mathrm{O}$ caso do Douro. Vila Real: Universidade de Trás-os-Montes e Alto Douro, 2009.

PIMENTEL, Emanuelle de Melo. Estratégias para a gestão da sazonalidade: a oferta turística algarvia. Dissertação de Mestrado. Aveiro: Universidade de Aveiro, 2008.

PIRES, Ana. Plano de negócios: Turismo em Espaço Rural na Serra de Tomar. Dissertação de Mestrado. Estoril: Escola Superior de Hotelaria e Turismo do Estoril, 2013. QUIVY Raymond ; CAMPENHOUDT, Luc. Manual de investigação em ciências sociais. 3 a ed. Tradução: Joiio Minhoto, Maria Amdlia Mendes e Maria Carvalho. Lisboa: Gradiva, 2003.

SEMEDO, Pedro. O impacto dos eventos culturais na renovação do produto turístico urbano - $O$ caso de Tomar. Dissertação de Mestrado em Gestão. Aveiro: Universidade de Aveiro, 2008.

SOUSA, Bruno; SIMÕES, Cláudia. Comportamento e perfil do consumidor. Revista de Estudos Politécnicos, VIII(14), pp.137-146, 2010.

TOMAR - CIDADE TEMPLÁRIA. Tomar - Cidade Templária. Retirado de http://www. cmtomar.pt/pt/, 2015.

Nova_Pagina_Inicial.htm

TURISMO DO CENTRO. Turismo do Centro. Retirado de http://www.

turismodocentro.pt/pt/, 2015.

TURISMO DE PORTUGAL, I.P. Plano Estratégico Nacional do Turismo [PENT]. Lisboa: Ministério da Economia, da Inovação e do Desenvolvimento, 2007.

TURISMO DE PORTUGAL, I.P. Plano Estratégico Nacional do Turismo [PENT]. Propostas para revisão no horizonte 2015 - versão 2.0. Lisboa: Ministério da Economia, da Inovação e do Desenvolvimento, 2007. 